\title{
Self-reported chronic pain is associated with physical performance in older people leaving aged care rehabilitation
}

\author{
Leani Souza Máximo \\ Pereira $^{1,2}$ \\ Catherine Sherrington ${ }^{2,3}$ \\ Manuela L Ferreira ${ }^{2}$ \\ Anne Tiedemann ${ }^{2,3}$ \\ Paulo H Ferreira ${ }^{4}$ \\ Fiona $\mathrm{M} \mathrm{Blyth}^{5}$ \\ Jacqueline CT Close Cl, $^{3}$ \\ Morag Taylor ${ }^{3,6}$ \\ Stephen R Lord ${ }^{3}$ \\ 'Department of Physiotherapy, \\ School of Physical Education, \\ Physiotherapy, and Occupational \\ Therapy, Universidade Federal de \\ Minas Gerais, Belo Horizonte, Brazil; \\ ${ }^{2}$ Musculoskeletal Division, The \\ George Institute for Global Health, \\ The University of Sydney, Sydney, \\ Australia; ${ }^{3}$ Neuroscience Research \\ Australia, University of New South \\ Wales, Sydney, Australia; ${ }^{4}$ Discipline \\ of Physiotherapy, Faculty of Health \\ Sciences, The University of Sydney, \\ Sydney, Australia; ${ }^{5}$ Pain Management \\ and Research Institute, Royal North \\ Shore Hospital, The University of \\ Sydney, Sydney, Australia; 'Prince of \\ Wales Clinical School, University of \\ New South Wales, Sydney, Australia
}

Correspondence: Leani Souza Máximo Pereira

Departamento de Fisioterapia, Escola de Ed Fisica Fisioterapia e T Ocupacional, Universidade Federal de Minas Gerais, Av Antonio Carlos 6627, Pampulha, Belo Horizonte, CEP 3I 270 90I, Brasil Tel +55 3l 3409478 I

Email leanismp.bh@terra.com.br
This article was published in the following Dove Press journal:

Clinical Interventions in Aging

5 February 2014

Number of times this article has been viewed

Background/objectives: The impact of pain on the physical performance of patients in aged care rehabilitation is not known. The study sought to assess 1) the prevalence of pain in older people being discharged from inpatient rehabilitation; 2) the association between self-reported pain and physical performance in people being discharged from inpatient rehabilitation; and 3) the association between self-reported pain and physical performance in this population, after adjusting for potential confounding factors.

Methods: This was an observational cross-sectional study of 420 older people at two inpatient aged care rehabilitation units. Physical performance was assessed using the Lower Limb Summary Performance Score. Pain was assessed with questions about the extent to which participants were troubled by pain, the duration of symptoms, and the impact of chronic pain on everyday activity. Depression and the number of comorbidities were assessed by questionnaire and medical file audit. Cognition was assessed with the Mini-Mental State Examination.

Results: Thirty percent of participants reported chronic pain (pain lasting more than 3 months), and $17 \%$ reported that this pain interfered with daily activities to a moderate or greater extent. Chronic pain $(P=0.013)$ and chronic pain affecting daily activities $(P<0.001)$ were associated with a poorer Lower Limb Summary Performance Score. The relationship between chronic pain affecting daily activities and Lower Limb Summary Performance Score remained significant $(P=0.001)$ after adjusting for depression, age, comorbidities, and Mini-Mental State Examination score. This model explained $10 \%$ of the variability in physical performance.

Conclusion: One-third of participants reported chronic pain, and close to one-fifth reported that this pain interfered with daily activities. Chronic pain was associated with impaired physical performance, and this relationship persisted after adjusting for likely confounding factors.

Keywords: pain, older people, physical performance, rehabilitation

\section{Introduction}

Pain is one of the most common reasons for older people to seek medical attention. ${ }^{1}$ There is some evidence that even though the prevalence of pain does not appear to increase with age, pain-related disability does increase. ${ }^{2}$ Of relevance to an aging population, people reporting pain and moderate-to-severe levels of pain-related disability are more likely to report falls than those not reporting pain, ${ }^{2}$ and pain that interferes with daily activities is significantly associated with frailty in older men. ${ }^{3}$ Most older adults who seek advice from health care professionals present with multiple health problems. The most frequent combinations of presenting problems have been found to be arthritis/chronic back pain and vascular disease (15\%), and arthritis/chronic back pain and psychological problems $(11 \%){ }^{4}$ 
Impaired physical performance, as measured by the Short Physical Performance Battery (SPPB), has been identified as a strong predictor of future disability, decreased mobility, ${ }^{5}$ institutionalization, and mortality in older people. ${ }^{6}$ Moreover, pain has been associated with poorer physical performance (as measured by the SPPB) in community-dwelling older people. ${ }^{7}$ Bryant et al found that chronic pain, but not pain intensity, had an independent association with worsening physical performance in 925 community-dwelling older men and women. ${ }^{8}$ Multiple sites of pain was also found to be significantly associated with poorer SPPB performance, after adjusting for age, sex, height, and weight, in 600 communitydwelling elders. ${ }^{9}$

Previous studies by our research group have found that lasting disability and falls are common among older people who have recently been hospitalized ${ }^{10,11}$ and that pain is associated with poorer stair negotiation, ${ }^{12} 6$-minute walk distance,,${ }^{13} 6 \mathrm{~m}$ walking speed, ${ }^{14}$ and sit-to-stand ${ }^{15}$ performance among community-dwelling older people. However, the influence of pain on the physical performance of older people who have been hospitalized has not been well investigated. Establishing the relationship between pain and physical performance in older patients at hospital discharge has important clinical implications for both patient prognosis as well as post-hospitalization treatment planning. The relationship between pain and physical performance in older people may also be confounded by other factors, such as depression, age, other health conditions, and cognition, which impact on both pain and physical performance. ${ }^{27}$ Cognitive impairment among older people presents a substantial barrier to pain assessment and treatment, and a strong direct association was observed in older patients, between chronic pain and depression. ${ }^{29,30}$ The present study aimed to assess 1) the prevalence of pain in older people being discharged from inpatient rehabilitation; 2) the association between pain and physical performance in this population; and 3) the association between pain and physical performance, after adjusting for potential confounding factors.

\section{Methods}

\section{Design}

This cross sectional study involved secondary analysis of predischarge assessment data from a prospective cohort study conducted at two inpatient aged care rehabilitation units in Sydney, Australia. ${ }^{10,11-16}$

\section{Participants}

The sample comprised 420 participants who had been hospitalized for a range of conditions. The primary reason for admission was a musculoskeletal problem (29\%), a neurological problem $(8 \%)$, a fall $(8 \%)$, or another medical condition $(8 \%)$ or procedure $(11 \%)$.

The Mini-Mental Status Examination Score ${ }^{17}$ (MMSE) was administered by the nursing or physiotherapy staff on the participating wards or, if this had not been done, by the study physiotherapist. Informed consent was sought from individuals with a MMSE score of 24 or more. Those with a MMSE score of less than 24 who were judged by the study physiotherapist to be able to perform the physical tests were included in the study if they agreed to participate and if a "responsible person" (a family member or caregiver who had agreed to act on their behalf) gave informed consent.

The study was approved by the Human Research Ethics Committees of the University of Sydney and the participating hospitals. More detailed methods have been published elsewhere. ${ }^{10,11-16}$

\section{Measures}

Data on the sociodemographic descriptors (age, gender) and health (diagnosis) of the study sample were collected from participating patients' medical records. A questionnaire and a physical performance assessment were administered by a trained physiotherapist within 48 hours prior to discharge from the ward.

The questionnaire included questions about pain and health conditions and symptoms (to supplement information obtained from medical records). Pain was assessed using three questions:

1. Are you currently troubled by pain or discomfort, either all the time or on and off?

2. Have you had this pain or discomfort for more than 3 months?

3. Does this pain affect your daily activities?

The provided responses to the first question were "yes" and "no," and the responses to questions 2 and 3 used a five-point scale ( $1=$ not at all, $2=$ a little bit, $3=$ moderately, $4=$ quite a lot, $5=$ extremely).The answers to these questions were dichotomized for analysis as "moderately to extremely" and "not at all to a little." The subjects were also asked about the distribution of pain and the presence of a range of health conditions and symptoms reported in the medical records, including depression and arthritis. Chronic pain is a subjective experience which is best measured in pragmatic terms, rather than considering intensity only. ${ }^{18}$

A list of possible health conditions and symptoms (including depression) was developed. The total number of 
these that affected each participant was obtained from the medical record and the questionnaire.

Cognitive status was assessed using the MMSE,${ }^{17}$ which was also used as part of the study entry process as described above. The MMSE has been found to have good reliability ${ }^{17}$ and has been validated against a variety of other cognitive functioning tests in a wide variety of populations. ${ }^{17}$

The physical assessment included measurement of the three items used to calculate the Lower Limb Summary Perof the SPPB, which has been identified as a strong predictor and mortality in older people. ${ }^{6}$ The SPPB/LLSPS involves the timed performance on three tests: standing balance, sit-tostand ability, and gait speed. Standing balance was calculated as the sum of the durations that each of three positions (feet together, semitandem stance, and tandem stance) could be held without assistance or arm support, with a maximum of 10 seconds for each stance. Sit-to-stand ability was measured by recording the time to complete five stands from a $45 \mathrm{~cm}$ chair, without assistance from another person or arm support. Gait speed was measured over $4 \mathrm{~m}$. For the LLSPS, scaled scores are added to give a total score, for which the maximum possible value is 3 . For easier interpretation, we converted this value to a score out of 30 . Previous studies have shown this instrument to have adequate intratest (intraclass correlation coefficient $[\mathrm{ICC}]=0.89$ for the gait test; $\mathrm{ICC}=0.73$ for the chair lift test, and ICC $=0.97$ for the balance test) and intertest reliability (ICC $=0.87$ to 0.97 for walking speed; and ICC $=0.93-0.99$ for chair lift test). ${ }^{6,19}$ As older patients may under- or overestimate their functional abilities, direct measures of physical performance are likely to produce more accurate results.

\section{Statistical analyses}

Descriptive statistics were used to describe the sample, estimate the prevalence of pain, and to summarize the questionnaire responses and physical performance. Univariate and multivariate linear regression models were used to quantify the associations between the outcome (ie, the dependent variable, physical performance, as measured by the LLSPS), the explanatory variables (ie, the independent variable, self-reported pain), and the covariates. The variables to be included in the analyses were chosen a priori. The pain variables were participant reports of: being troubled by pain ("moderately or more"), chronic pain (defined as having pain for more than 3 months), having pain for more than 3 months that affected daily activities ("moderately or formance Score (LLSPS), ${ }^{19}$ the continuously scored version of future disability, decreased mobility, ${ }^{5}$ institutionalization,

more"), and having back pain/lower limb pain. The covariates examined were arthritis in the lower limbs or spine, depression, gender, age, total number of participant-reported health conditions and symptoms, and cognitive status (MMSE score).

Univariate analyses were conducted to assess the relationship between physical performance (LLSPS score) and 1) each of the pain variables, and 2) each of the covariates. The pain variables with the strongest relationship with physical performance (ie, chronic pain affecting daily activities) were then entered into a multivariate model, which also included each of the covariates that were significantly associated with outcome in the univariate analyses (ie, depression, age, comorbidities, and MMSE score). A $P$-value of less than 0.05 was considered significant for all analyses. The analyses were conducted using the SPSS/ PASW 18.0 (SPSS Inc, Chicago, IL, USA) and Stata 10 (StataCorp, College Station, TX, USA) statistical software packages.

\section{Results}

Data on all measures were available for 420 participants. The participant characteristics are shown in Table 1. Seventyone percent (296) of participants reported being troubled by pain at discharge, and 30\% (128) reported being affected by

Table I Characteristics of the study participants $(n=420)$

\begin{tabular}{|c|c|}
\hline Characteristic & \\
\hline Age (yr), mean (SD) & $81.5(8.2)$ \\
\hline Females, n (\%) & $296(70)$ \\
\hline \multicolumn{2}{|l|}{ Troubled by pain, $\mathrm{n}(\%)$} \\
\hline Not at all & $123(29)$ \\
\hline A little & $127(30)$ \\
\hline Moderately & II $6(28)$ \\
\hline Quite a lot & $49(12)$ \\
\hline Extremely & $5(I)$ \\
\hline Pain for more than 3 months, $\mathrm{n}(\%)$ & $128(30)$ \\
\hline \multicolumn{2}{|l|}{ Pain affecting daily activities lasting for more than } \\
\hline \multicolumn{2}{|l|}{3 months, $\mathrm{n}(\%)$} \\
\hline Not at all & $16(14)$ \\
\hline A little & $42(35)$ \\
\hline Moderately & $36(27)$ \\
\hline Quite a lot & $32(24)$ \\
\hline Extremely & $0(0)$ \\
\hline Pain in the lower limbs or back lasting for more than & $82(20)$ \\
\hline \multicolumn{2}{|l|}{3 months, $\mathrm{n}(\%)$} \\
\hline Arthritis in the lower limbs or spine, $n(\%)$ & $300(7 I)$ \\
\hline $\begin{array}{l}\text { Total number of health conditions or symptoms, } \\
\text { mean (SD) }\end{array}$ & $8.3(3.2)$ \\
\hline Cognition (MMSE), mean (SD) & $25.7(4.2)$ \\
\hline Presence of self-reported depression, $\mathrm{n}(\%)$ & $95(23)$ \\
\hline Lower Limb Summary Performance Score (/30), mean (SD) & 16.1 (4.1) \\
\hline
\end{tabular}


chronic pain (ie, pain lasting at least 3 months). In 17\% of the participants ( 70 people), chronic pain at least moderately affected daily activities.

As Table 2 shows, chronic pain $(P=0.013)$, chronic pain affecting daily activities $(P<0.001)$, depression $(P=0.027)$, number of comorbidities and symptoms $(P<0.001)$, lower MMSE score $(P=0.002)$, and age $(P<0.001)$ were associated with worse physical performance (lower LLSPS). There were smaller associations, which did not reach statistical significance, between reports of being troubled by pain $(P=0.285)$, pain in the legs or back $(P=0.125)$, arthritis in the lower limbs or spine $(P=0.227)$ and worse physical performance. There was no indication of an effect of gender on physical performance $(P=0.789)$. The variability in physical performance explained by each individual variable was low $\left(r^{2}<3 \%\right)$.

The impact of pain of more than 3 months duration affecting daily activities on LLSPS persisted $(P=0.001)$ after adjustment for depression, age, number of comorbidities, and cognitive status (Table 3 ).

\section{Discussion}

Thirty percent of this sample of older people at the point of discharge from hospital reported having pain that had lasted more than 3 months. This is higher than the average prevalence of chronic pain (23\%) in Australians aged $75-84 .{ }^{28}$ Desbiens et al found a $46 \%$ prevalence of pain in hospitalized older people, with the symptoms persisting for up to 12 months postdischarge. ${ }^{20}$ Several reasons could explain this high prevalence of chronic pain among older people at discharge from hospital. For instance, a number of pain medications commonly prescribed for chronic pain cannot be administered in this population because of the presence of comorbidities, such as congestive heart failure, peptic ulcer disease, cognitive impairment, and disorders requiring anticoagulant therapy - all of which are highly prevalent in older people. ${ }^{21}$

The present study found that chronic pain had a significant impact on physical performance. Participants who reported being currently troubled by pain or discomfort did not demonstrate significantly poorer LLSPS scores $(P=0.285)$, but LLSPS scores were lower in people who reported experiencing this pain for more than 3 months. Similarly, a previous study in community-dwelling older people found that pain duration rather than intensity was associated with impaired physical performance. ${ }^{8}$ The duration of pain for long periods causes behavioral and cognitive alterations, and morphological and chemical changes in the brain..$^{29,30,31}$ Moreover, other

Table 2 Univariate linear regression analysis of the association between explanatory variables and LLSPS ( $n=420)$

\begin{tabular}{|c|c|c|c|c|}
\hline Explanatory variable & $\begin{array}{l}\text { LLSPS score, } \\
\text { mean (SD) }\end{array}$ & $\begin{array}{l}\text { Coefficient } \\
\text { (95\% Cl) }\end{array}$ & $\begin{array}{l}\text { Standardized } \\
\text { coefficient }\end{array}$ & $P$-value \\
\hline \multicolumn{5}{|l|}{ Troubled by pain } \\
\hline Not at all/a little, $n=250$ & $16.2(4.2)$ & $-0.43(-1.23$ to 0.36$)$ & -0.05 & 0.285 \\
\hline Moderately to extremely, $n=\mid 70$ & $15.8(3.8)$ & & & \\
\hline \multicolumn{5}{|l|}{ Pain for more than 3 months } \\
\hline No, $n=292$ & $16.4(4.1)$ & $-1.07(-1.91$ to -0.23$)$ & -0.12 & 0.013 \\
\hline Yes, $\mathrm{n}=128$ & $15.3(3.9)$ & & & \\
\hline \multicolumn{5}{|l|}{ Chronic pain affecting daily activities } \\
\hline Not at all/a little, $n=349$ & $16.4(4.0)$ & $-2.08(-3.11$ to -1.05$)$ & -0.19 & $<0.001$ \\
\hline Moderately to extremely, $n=70$ & $14.3(4.2)$ & & & \\
\hline \multicolumn{5}{|l|}{ Chronic lower limb or back pain } \\
\hline No, $n=327$ & $16.2(4.0)$ & $-0.76(-1.74$ to 0.21$)$ & -0.08 & 0.125 \\
\hline Yes, $\mathrm{n}=82$ & $15.5(3.9)$ & & & \\
\hline \multicolumn{5}{|l|}{ Arthritis in lower limbs/ spine } \\
\hline No, $n=120$ & I6.4 (4.5) & $-0.53(-1.4$ to 0.33$)$ & -0.06 & 0.227 \\
\hline Yes, $n=300$ & $15.9(3.9)$ & & & \\
\hline \multicolumn{5}{|l|}{ Depression } \\
\hline No, $n=325$ & $16.3(3.7)$ & $-1.1(-2.0$ to -0.12$)$ & -0.11 & 0.027 \\
\hline Yes, $n=95$ & $15.3(5.0)$ & & & \\
\hline \multicolumn{5}{|l|}{ Gender } \\
\hline Women, $\mathrm{n}=296$ & $16.0(4.0)$ & $0.12(-0.74$ to 0.97$)$ & 0.01 & 0.789 \\
\hline Men, $\mathrm{n}=124$ & $16.2(4.2)$ & & & \\
\hline Age & & $-0.09(-0.14$ to -0.05$)$ & -0.19 & $<0.001$ \\
\hline Number of co morbidities & & $-0.27(-0.39$ to -0.15$)$ & -0.21 & $<0.001$ \\
\hline MMSE score & & $0.14(0.05$ to 0.23$)$ & 0.15 & 0.002 \\
\hline
\end{tabular}

Abbreviations: $\mathrm{Cl}$, confidence interval; LLSPS, Lower Limb Summary Performance Score; MMSE, Mini-Mental State Examination; SD, standard deviation. 
Table 3 Multivariate linear regression analysis of the association between chronic pain affecting daily activities and LLSPS $(n=420)$

\begin{tabular}{llll}
\hline $\begin{array}{l}\text { Explanatory } \\
\text { variable }\end{array}$ & Coefficient $(95 \% \mathrm{Cl})$ & $\begin{array}{l}\text { Standardized } \\
\text { coefficient }\end{array}$ & P-value \\
\hline $\begin{array}{l}\text { Pain affecting } \\
\text { daily activities }\end{array}$ & $-1.78(-2.81$ to -0.76$)$ & -0.16 & 0.001 \\
Depression & $-0.64(-1.59$ to 0.30$)$ & -0.07 & 0.180 \\
Age & $-0.07(-0.12$ to -0.02$)$ & -0.15 & 0.003 \\
Number of & $-0.15(-0.28$ to -0.02$)$ & -0.11 & 0.028 \\
comorbidities & & & \\
MMSE score & $0.11(0.02$ to 0.20$)$ & 0.12 & 0.015 \\
\hline
\end{tabular}

Note: The adjusted $R^{2}$ (proportion of variability in LLSPS score explained) for this model was $10 \%$.

Abbreviations: $\mathrm{Cl}$, confidence interval; LLSPS, Lower Limb Summary Performance Score; MMSE, Mini-Mental State Examination.

evidence also indicates that the intensity of the pain also diminishes functional capacity. ${ }^{22}$

We found even lower LLSPS scores in participants who reported chronic pain that interfered with daily activities $(P=0.002)$. These results suggest that severity of pain also plays an important role in the development of disability and functional impairment in older people. Similar findings were reported by Weaver et al, from a study of over 1,000 older men. ${ }^{23}$ Men with moderate and severe self-reported pain affecting daily life in the preceding 4 weeks were found to have significantly lower scores on activities of daily living (ADL), instrumental activities of daily living (IADL), and SPPB. ${ }^{23}$ Blyth et al also found that pain that interfered with daily work was significantly associated with frailty in older men, defined in terms of weight loss, muscle weakness, exhaustion, gait slowness, and low activity. ${ }^{3}$

Impaired physical performance may increase the risk of falls in older people with pain. Hubscher et al found that patients with pain were 6.4 times $(6.4=$ odds ratio) $(95 \%$ confidence interval [CI]: 1.5-26.7) more likely to have low falls-efficacy (low perceived self-efficacy at avoiding falls during essential, nonhazardous activities of daily living) and to perform badly in tests of quadriceps strength, postural sway, and gait speed, ${ }^{24}$ placing them at an increased risk of future falls. It has also been shown that people who report pain and pain-related disability are more likely to report falls than those who do not report pain. ${ }^{2}$

Poorer LLSPS was also associated with increased age in our study. These results are consistent with those of Miller et $\mathrm{a}^{25}$ who demonstrated that decline in SPPB score was associated with older age (as well as low falls self-efficacy, poor vision, presence of diabetes mellitus, obesity, hospitalization in the preceding year, and kidney disease). Therefore, assessment of pain is important in all ages. Previous research has shown that people with pain develop functional limitations classically associated with aging at earlier ages. ${ }^{25}$ People with high levels of pain are found to present similar degrees of functional limitations to those 20 to 30 years older.

To our knowledge, this is the first study to assess the impact of pain on a performance-based measure of mobility in older people at discharge from hospital. Previous studies to assess the impact of pain on lower extremity function have used selfreported measures of physical function ${ }^{22-26}$ or have been conducted with community-dwelling older people. ${ }^{23}$ Mossey et $\mathrm{al}^{27}$ have shown that in independently living retirement community residents, both pain and depression influence physical performance. Our data did not support the influential factor of depression but corroborate the influence of pain in performance.

The relatively large sample size was a strength of this study, but the study was not without limitations. We attempted to include all eligible inpatients in the study but as outlined in our previous publications from this study, ${ }^{10,11-16}$ a total of 1,127 people were admitted to the wards during the study period. We experienced some logistical difficulties in that research personnel could not always be present when patient assessments were required. Some people with cognitive impairment were excluded as we were unable to contact the "responsible person" to gain consent. The inclusion of people with cognitive impairment may also have had an impact on the accuracy of the responses to time-related questions and physical assessments. In addition, as a result of the rehabilitation ward setting, our study participants all had mobility problems and had all undergone rehabilitation programs for these problems, and caution is required when considering the results in the context of other populations of older people. Approximately two-thirds of the included sample were female; however, based on the main reasons for exclusion from the study (lack of availability of a caregiver to give consent, lack of availability of hospital staff), it is unlikely that selection bias affected our results. ${ }^{10}$ The higher proportion of women in the study probably reflects the gender mix of patients admitted to the ward during this time (although data are not available to confirm this).

Since this was a secondary analysis study, we did not have the opportunity to include any specific pain assessment tool that could provide evidence of some more specific features of pain in our sample or to specify other elements related to depression or other comorbidities that could be relevant to this sample. There is also a risk that the study findings could have been due to type 1 error, given the number of analyses undertaken, yet the strength of the relationship between pain and physical performance and the precision of the estimates suggest a true relationship. 
The size of the contribution of the explanatory variables to the LLSPS was relatively small, despite being statistically significant. The LLSPS is a mobility test involving the complex integration of multiple functions, and thus, age-related changes in other components of the sensorimotor system, such as muscle strength, neuromuscular coordination, vision, and proprioception are likely to have an impact on older people's physical performance. ${ }^{13-15}$

The LLSPS is composed of mobility tasks similar to those of daily life and was designed to assess physical performance in older people. People with chronic pain may be reluctant to perform physical tests to their maximum ability, due to concerns about exacerbating pain. The association between pain and poor physical performance may also be exacerbated by inactivity. As this was a cross-sectional observational study, inferences on causation cannot be made. Future studies could investigate whether chronic pain management strategies in older people with impaired mobility lead to improved physical performance. These insights could be used in future clinical trials, to design interventions to help older adults more effectively deal with chronic pain.

In summary, our results show that chronic pain was reported by one-third of older people at the time of discharge from inpatient aged care rehabilitation and was associated with impaired physical performance. Close to one-fifth of the participants reported that their chronic pain interfered with daily activities. Chronic pain that was reported to affect daily activities was more strongly associated with impaired physical performance than wad chronic pain per se. The association between chronic pain that affected daily activities and impaired physical performance persisted after adjusting for a number of covariates. This information can be used for better management of pain-related disability in this population, which could in turn contribute to improvements in everyday function and the quality of life in older people being discharged from inpatient rehabilitation.

\section{Author contributions}

C Sherrington, FM Blyth, SR Lord, JCT Close, and A Tiedemann conceptualized and designed the study. M Taylor collected the data. Data analysis was undertaken by LSM Pereira, C Sherrington, ML Ferreira, and PH Ferreira. All authors contributed to the interpretation of the data, and in the preparation and critical revision of the manuscript.

\section{Acknowledgments}

This work was supported by the New South Wales Health Department. C Sherrington, SR Lord, and A Tiedemann are funded by Australian National Health and Medical Research Council Fellowships. F Blyth was supported by the Ageing and Alzheimer's Research Foundation. LSM Pereira was funded by a fellowship from CAPES (Coordenação de Aperfeiçoamento de Pessoal de Nível Superior, Brazil). The sponsors played no role in the design or execution of the study, analysis and interpretation of data, or writing of the manuscript.

The authors thank E Barraclough for assisting with data collection.

\section{Disclosure}

The authors report no conflicts of interest in this work.

\section{References}

1. Hasselström J, Liu-Palmgren J, Rasjö-Wrååk G. Prevalence of pain in general practice. Eur J Pain. 2002;6(5):375-385.

2. Macfarlane GJ, Beasley M, Jones EA, et al; Musician Study Team. The prevalence and management of low back pain across adulthood: Results from a population-based cross-sectional study (the MUSICIAN study). Pain. 2012;153(1):27-32.

3. Blyth FM, Rochat S, Cumming RG, et al. Pain, frailty and comorbidity on older men: the CHAMP study. Pain. 2008;140(1):224-230.

4. Britt H, Miller GC, Charles J, et al. General Practice Activity in Australia. 2007-08. Canberra: Australian Institute of Health and Welfare; 2008.

5. Guralnik JM, Ferrucci L, Pieper CF, et al. Lower extremity function and subsequent disability: consistency across studies, predictive models, and value of gait speed alone compared with the short physical performance battery. J Gerontol A Biol Sci Med Sci. 2000;55(4):M221-M231.

6. Guralnik JM, Simonsick EM, Ferrucci L, et al. A short physical performance battery assessing lower extremity function: association with self-reported disability and prediction of mortality and nursing home admission. J Gerontol. 1994;49(2):M85-M94.

7. Cecchi F, Molino-Lova R, Di Iorio A, et al. Measures of physical performance capture the excess disability associated with hip pain or knee pain in older persons. J Gerontol A Biol Sci Med Sci. 2009;64(12): 1316-1324.

8. Bryant LL, Grigsby J, Swenson C, Scarbro S, Baxter J. Chronic pain increases the risk of decreasing physical performance in older adults: the San Luis Valley Health and Aging Study. J Gerontol A Biol Sci Med Sci. 2007;62(9):989-996.

9. Eggermont LH, Bean JF, Guralnik JM, Leveille SG. Comparing pain severity versus pain location in the MOBILIZE Boston study: chronic pain and lower extremity function. J Gerontol A Biol Sci Med Sci. 2009;64(7):763-770.

10. Sherrington C, Lord SR, Close JC, et al. Mobility-related disability three months after aged care rehabilitation can be predicted with a simple tool: an observational study. J Physiother. 2010;56(2):121-127.

11. Sherrington C, Lord SR, Close JC, et al. A simple tool predicted probability of falling after aged care inpatient rehabilitation. $J$ Clin Epidemiol. 2011;64(7):779-786.

12. Tiedemann AC, Sherrington C, Lord SR. Physical and psychological factors associated with stair negotiation performance in older people. J Gerontol A Biol Sci Med Sci. 2007;62(11):1259-1265.

13. Lord SR, Menz HB. Physiologic, psychologic, and health predictors of 6-minute walk performance in older people. Arch Phys Med Rehabil. 2002;83(7):907-911.

14. Tiedemann A, Sherrington C, Lord SR. Physiological and psychological predictors of walking speed in older community-dwelling people. Gerontology. 2005;51(6):390-395. 
15. Lord SR, Murray SM, Chapman K, Munro B, Tiedemann A. Sit-to-stand performance depends on sensation, speed, balance, and psychological status in addition to strength in older people. J Gerontol A Biol Sci Med Sci. 2002;57(8):M539-M543.

16. Sherrington C, Lord SR, Close JC, et al. Development of a tool for prediction of falls in rehabilitation settings (Predict_FIRST): a prospective cohort study. J Rehabil Med. 2010;42(5):482-488.

17. Folstein MF, Folstein SE, McHugh PR. «Mini-mental state». A practical method for grading the cognitive state of patients for the clinician. J Psychiatr Res. 1975;12(3):189-198.

18. Purves AM, Penny K, Munro C, et al. Defining chronic pain for epidemiological research: assessing a subjective definition. The Pain Clinic. 1998;10:139-147.

19. Onder G, Penninx BW, Ferrucci L, Fried LP, Guralnik JM, Pahor M. Measures of physical performance and risk for progressive and catastrophic disability: results from the Women's Health and Aging Study. J Gerontol A Biol Sci Med Sci. 2005;60(1):74-79.

20. Desbiens NA, Mueller-Rizner N, Connors AF, Hamel MB, Wenger NS Pain in the oldest-old during hospitalization and up to one year later. HELP Investigators. Hospitalized Elderly Longitudinal Project. J Am Geriatr Soc. 1997;45(10):1167-1172.

21. Reid MC, Papaleontiou M, Ong A, Breckman R, Wethington E, Pillemer K. Self-management strategies to reduce pain and improve function among older adults in community settings: a review of the evidence. Pain Med. 2008;9(4):409-424.

22. Samwel HJ, Evers AW, Crul BJ, Kraaimaat FW. The role of helplessness, fear of pain, and passive pain-coping in chronic pain patients. Clin $J$ Pain. 2006;22(3):245-251.
23. Weaver GD, Kuo YF, Raji MA, et al. Pain and disability in older Mexican-American adults. J Am Geriatr Soc. 2009;57(6):992-999.

24. Hübscher M, Vogt L, Schmidt K, Fink M, Banzer W. Perceived pain, fear of falling and physical function in women with osteoporosis. Gait Posture. 2010;32(3):383-385.

25. Miller DK, Wolinsky FD, Andresen EM, Malmstrom TK, Miller JP. Adverse outcomes and correlates of change in the Short Physical Performance Battery over 36 months in the African American health project. J Gerontol A Biol Sci Med Sci. 2008;63(5):487-494.

26. Apkarian AV, Sosa Y, Sonty S, et al. Chronic back pain is associated with decreased prefrontal and thalamic gray matter density. J Neurosci. 2004;24(46):10410-10415.

27. Mossey JM, Gallagher RM, Tirumalasetti F. The effects of pain and depression on physical functioning in elderly residents of a continuing care retirement community. Pain Med. 2000;1(4):340-350.

28. Blyth FM, March LM, Barnabic AJ, Jorm LR, Williamson M, Cousins MJ. Chronic pain in Australia: a prevalence study. Pain. 2001;89(2-3):127-134.

29. Turk DC, Okifuji A, Scharff L. Chronic pain and depression: role of perceived impact and perceived control in different age cohorts. Pain. 1995;61(1):93-101.

30. Ferrell BA, Ferrell BR, Rivera L. Pain in cognitively impaired nursing home patients. J Pain Symptom Manage. 1995;10(8):591-598.

31. Grachev ID, Fredrickson BE, Apkarian AV. Abnormal brain chemistry in chronic back pain: an in vivo proton magnetic resonance spectroscopy study. Pain. 2000;89(1):7-18.
Clinical Interventions in Aging

\section{Publish your work in this journal}

Clinical Interventions in Aging is an international, peer-reviewed journal focusing on evidence-based reports on the value or lack thereof of treatments intended to prevent or delay the onset of maladaptive correlates of aging in human beings. This journal is indexed on PubMed Central, MedLine, the American Chemical Society's 'Chemical Abstracts

\section{Dovepress}

Service' (CAS), Scopus and the Elsevier Bibliographic databases. The manuscript management system is completely online and includes a very quick and fair peer-review system, which is all easy to use. Visit http://www.dovepress.com/testimonials.php to read real quotes from published authors. 